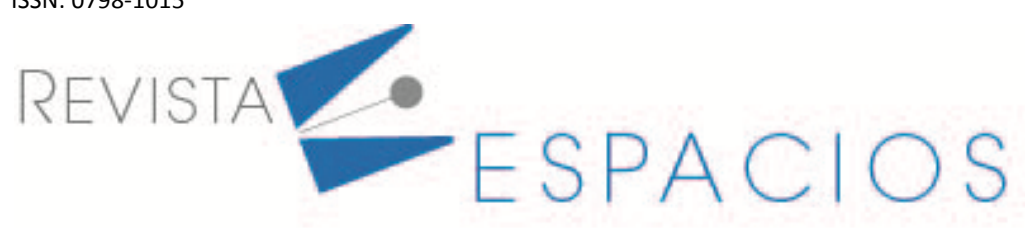

\title{
Pandemia, libertad y futuro ¿Qué piensan los jóvenes de la situación actual?
}

\section{Pandemic, freedom and future. What do young people think of the current situation?}

\author{
RAMAS-ARAUZ, Francisco E. ${ }^{1}$ \\ LÓPEZ-LOZADA, Gerardo ${ }^{2}$ \\ FREIXAS, Rosario 3
}

\section{Resumen}

El estudio busca rescatar, a través de las redes semánticas naturales, las voces de los alumnos respecto a la crisis sanitaria causada por el SARSCOV-2. Por ello, gira en torno a su visión subjetiva sobre la crisis a partir de tres términos inductores: pandemia, libertad y futuro. La población del estudio corresponde a estudiantes de licenciatura de la UNAM. Los resultados obtenidos arrojan una aproximación al sentir de la población estudiantil frente a un hecho tan complejo.

Palabras clave: significados, subjetividad, pandemia, libertad, futuro

\begin{abstract}
This paper endeavors to give voice to the perspectives of students with regard to the sanitary crisis caused by the SARS-Cov2 virus by using natural semantic networks as a tool for data collection. The article revolves around the students' subjective vision on the sanitary crisis in the light of three inductive terms: pandemic, freedom, and future. The study population was composed of undergraduate students from UNAM. The results obtained show the widespread feeling of students regarding such complex phenomenon.
\end{abstract}

Key words: meanings, subjectivity, freedom, future

\section{Introducción}

Los sistemas educativos se están enfrentando a escenarios inimaginables debido a la pandemia causada por el virus SARS CoV-2, lo que los ha llevado a modificar la estructura tradicional de formación mediante diversas estrategias para encarar y sacar adelante los procesos educativos. Como respuesta a ello, los sistemas educativos y las personas mismas han tenido que desafiar sus límites y replantearse la manera de llevar las prácticas educativas a nuevos escenarios.

En la educación superior, como en todos los niveles educativos, el impacto de la pandemia ha sido significativo. La acelerada expansión del virus supuso un cambio para el que nadie estaba preparado: ni las instituciones, ni los profesores, ni el alumnado. Millones de estudiantes en todo el mundo y, según datos de la UNESCO (2020),

\footnotetext{
${ }^{1}$ Profesor. Facultad de Filosofía y Letras. Universidad Nacional Autónoma de México. franciscoramas@filos.unam.mx

2 Profesor. Facultad de Filosofía y Letras. Universidad Nacional Autónoma de Mëxico. gerardolopez@filos.unam.mx

3 Profesora. Escuela Nacional de Trabajo Social. Universidad Nacional Autónoma de México. freixas@unam.mx
} 
24 millones de ellos en el nivel superior -tan sólo en Latinoamérica- tuvieron que abandonar las aulas para continuar sus estudios en casa mediados por las tecnologías de la información y comunicación.

Los cambios en los modos de vida del alumnado y el profesorado pueden plantearse desde varias aristas y uno de los más drásticos es el descontrol temporal que ha originado: el tiempo parece haberse trastocado. El sentido de orden y planeación en la cotidianeidad de los días previos a la pandemia se ha quebrantado y, en su lugar, ha dejado una atmósfera de incertidumbre: no hay una fecha exacta para regresar a las aulas, muchos procesos se han detenido o -en el mejor de los casos- ralentizado; se han puesto de manifiesto las diferencias sociales y la crisis de empleo se ha agudizado, por mencionar sólo algunos inconvenientes.

Si bien es cierto que gran parte de la producción académica generada en los últimos meses ha reflejado diversos aspectos de la problemática causada por la crisis sanitaria, ésta se ha centrado estrictamente en la relación escuela-alumno y escuela-docente (los cambios en el procesos de enseñar y aprender en entornos no presenciales, la adaptación o el desarrollo de competencias tanto del alumnado como del profesorado para transitar en éstos, los modelos y las estrategias de enseñanza, las políticas educativas frente a la pandemia, entre otras).

El problema de investigación que aquí se plantea está enmarcado en la visión del alumnado respecto a la crisis sanitaria, es decir, busca la comprensión del momento histórico que se está viviendo. Si esta situación es inédita para la generación actual en el mundo de la educación y en la época contemporánea en general, ¿a qué referentes recurren los alumnos cuando reflexionan acerca de la pandemia? ¿qué implica en sus vidas y en su manera de articular su porvenir como individuos, más allá de ser estudiantes? El desarrollo de este estudio gira en torno a estos cuestionamientos.

Así, este artículo tiene como objetivo analizar los procesos orientados al conocimiento y comprensión de la visión particular de un grupo de estudiantes de diversas licenciaturas de la Universidad Nacional Autónoma de México (UNAM), acerca de la pandemia, el futuro y la libertad, en el contexto del confinamiento por la COVID-19. Para ello, se realizó una encuesta a 430 jóvenes estudiantes de pregrado y sus resultados fueron analizados bajo una perspectiva fenomenológica (Rodríguez, Gil y García, 2001) con la metodología de las redes semánticas naturales propuesta por Valdés (2005). Los resultados arrojaron una gran riqueza de significados que se asocian en una red semántica en la que convergen los tres núcleos estrechamente relacionados.

\subsection{El poder de las palabras}

El lenguaje, desde un punto ontológico, no es algo que se pueda reducir a un proceso sistemático lingüístico que conlleva a un mero fin comunicativo. El lenguaje da cuenta de la significación que cada individuo le da a su estar en el mundo, es decir, no es un simple recurso o instrumento del hombre, sino que éste habita en el lenguaje, por así decirlo, dado que cada experiencia vivida se manifiesta y cobra fuerza una vez que se materializa en las palabras.

En este sentido, conocer la perspectiva que una persona tiene sobre determinado suceso a través de asociaciones de palabras es vivir la experiencia del lenguaje a través del lenguaje, esto es, las palabras nos acercan a las vivencias personales de cada individuo. Una palabra, entendida como un signo lingüístico (Saussure, 1945), está compuesta por una imagen acústica, también conocida como significante, y un concepto, también conocido como significado. Para ejemplificar esto, la palabra fruta posee un significado concreto y abstracto en nuestra mente al mismo tiempo, ya que, aunque existe una amplia variedad de frutas diferentes, se generaliza con una sola palabra. Esto significa que un concepto representa regularidades que el cerebro percibe en hechos y objetos a través de la mente. 
Más allá de las palabras, Wittgenstein (1988: 20-59) explica que el lenguaje no es un espejo de la realidad, sino un instrumento para el desarrollo de la vida humana. El significado de una palabra está en el uso que se hace de ella en el lenguaje. Es palpable, además, la recurrente modificación en el significado de las palabras de acuerdo con la designación referida, así como el contexto en el que se utiliza y la intención en la comunicación (Cervera, s/a). Es por ello que conocer las asociaciones semánticas más recurrentes que el alumnado escribió a partir de tres términos inductores-pandemia, libertad y futuro- puede ofrecernos un panorama de cómo es que conciben su estar en el mundo en un escenario determinado.

\subsection{Pandemia, libertad y futuro: Tres palabras clave}

Las condiciones sociales, familiares, sanitarias y económicas actuales en que los y las jóvenes se desenvuelven, pero particularmente las educativas, pueden ser exploradas desde una óptica de análisis semántico a partir de tres términos clave que, como ya se mencionó, se eligieron para este estudio: pandemia, libertad y futuro. El primero de ellos enmarca un contexto acotado e hiperinformado; el segundo, la posibilidad de libertad de acción en este contexto restringido; y el tercero, la visión a largo plazo como resultado -o no- de las condiciones actuales. Por ello, a continuación, se presenta una revisión de cada uno de ellos que permite una referencia para enmarcar los resultados obtenidos en el estudio.

\section{Pandemia}

De acuerdo con la Organización Mundial de la Salud (OMS) (2020), una pandemia se refiere a la propagación de una nueva enfermedad en todo el mundo. Para catalogar una enfermedad como pandemia debe cumplir con los criterios de brote y epidemia. En epidemiología, el brote es una clasificación utilizada para describir la aparición repentina de enfermedades debido a una infección en un lugar específico y en un momento específico. El ejemplo más evidente de esta situación es la aparición de una intoxicación alimentaria, la cual provoca que el caso aparezca durante dos o tres días. Otro ejemplo es un brote de meningitis o sarampión, que puede durar de dos a tres meses.

Cuando la enfermedad no se puede controlar y se mantiene en el tiempo, se propaga activamente y se clasifica como epidemia. De esta forma, se incrementa el número de casos en un área geográfica específica. Para declarar un estado de pandemia, ya sea en un continente o en una región, se deben cumplir, por un lado, las dos condiciones mencionadas y, por otro, que los casos que surjan ya no sean importados, esto es, que sean causados por transmisión comunitaria. La OMS ha clasificado la situación actual de la COVID-19 como pandemia tras multiplicarse por 13 el número de casos fuera de China y triplicarse el número de países afectados.

El término cuarentena se entiende por limitar las actividades o aislar a las personas saludables pero que pueden haber estado expuestas a la COVID-19, buscando prevenir el contagio de la enfermedad cuando las personas comienzan a experimentar síntomas. Aislamiento, por su parte, significa dividir a pacientes con síntomas de COVID-19 y aislarlos para evitar o minimizar la propagación de la enfermedad. El distanciamiento hace referencia a estar físicamente separados. Al respecto, la OMS recomienda mantener una distancia de al menos un metro y medio entre sí. Es una medida general que todas las personas deberían adoptar incluso si se encuentran bien y no han tenido una exposición conocida a la COVID-19.

\section{Libertad}

Resulta evidente que los jóvenes que cursan educación superior gozan de una mayor libertad, independencia y decisión propia otorgada por sus familias, que aquellos que se encuentran en niveles educativos inferiores. El acceso a la educación superior confiere, educativamente, libertades en la toma de decisiones y una mayor independencia en el curso de sus estudios. 
Es posible que este momento se dé a partir de la decisión de qué carrera elegir, a qué universidad ingresar y, posteriormente, la selección de las asignaturas, de los profesores y de los horarios en los que llevarán sus clases. Además, la supervisión de los padres disminuye o desaparece al llegar a la adultez. Es en esta adultez temprana donde se comienza a vivir una libertad más amplia que es determinante en la configuración de la madurez.

Una libertad es una posibilidad de elección y, aunque esta afirmación puede parecer unívoca, Morin (2000) señala que puede ser interior, es decir, subjetiva o mentalmente posible; a esto lo denomina libertad de espíritu. Puede ser también exterior, objetiva o materialmente posible, lo que constituye una libertad de acción. Entendida, además, como una doble posibilidad entre gozar de libertad y tener libertades, resulta evidente que la modificación de la libertad impuesta desde afuera, es decir, por las autoridades sanitarias alrededor del mundo, está referida exclusivamente a la libertad de acción.

Las medidas adoptadas por los gobiernos en torno a la restricción de la movilidad, el uso de mascarillas y otras medidas de higiene, indiscutiblemente han mermado las libertades de las que gozaban los estudiantes hasta hace unos meses, al menos temporalmente. Estas medidas han causado polémica alrededor del orbe: muchos se han posicionado en contra de las medidas de aislamiento social impulsadas por los gobiernos, y se han desatado manifestaciones en diversos puntos bajo la premisa de que se atenta en contra de los derechos humanos, en contra de las libertades individuales.

\section{Futuro}

Anteriormente, proyectar un futuro estable desde la educación superior resultaba un ejercicio mucho más lineal y concreto que en la actualidad. Se podían concebir posibilidades en común entre los estudiantes tales como estudios posteriores, un trabajo estable, matrimonio, retiro, etc. (Mclnerney, 2004, 143). En la actualidad, dicha visión se ha desmoronado para dar paso a un modo de vida lleno de incertidumbre acrecentada por la pandemia; la mayoría de los trabajos hoy en día bien podrían ser considerados efímeros y muchos demandan un ritmo laboral excesivo acentuado por la pandemia, dado que los horarios laborales condicionados por espacios físicos han sido transgredidos tras la inclusión de la oficina en casa.

A esto hay que agregar que existen obstáculos inmediatos que socavan la posibilidad de tener una visión clara del futuro. La brecha digital, por ejemplo, se ha exacerbado a raíz de la pandemia; en México el $18 \%$ de los estudiantes de nivel superior no tienen acceso a internet (Lloyd, 2020, 117). No sorprende, entonces, que, como se explorará más adelante, el término futuro haya sido aquel con más coincidencias con los otros dos términos inductores, ya que, al ser algo impredecible de proyectar, puede bifurcarse en un espectro maniqueo en el que convergen tanto valores positivos como negativos.

\section{Metodología}

Debido a que el proyecto aborda aspectos relacionados con significados y conceptos de naturaleza experiencial de los sujetos, el tipo de investigación que se llevó a cabo es fenomenológica, ya que "busca conocer los significados que los individuos dan a su experiencia, lo importante es aprehender el proceso de interpretación por el que la gente define su mundo y actúa en consecuencia”. (Rodríguez, Gil y García, 2001:42)

Así, en la fenomenología, el investigador trata de describir, analizar, comprender e interpretar las cosas desde el punto de vista del otro. Dentro de este abordaje epistemológico, se utilizaron las redes semánticas naturales (RSN) para analizar los hallazgos obtenidos en el trabajo empírico por ser una técnica de investigación muy poderosa para la organización, comprensión y análisis de conceptos. Para Valdez (2005), las RSN se entienden como una metodología ideal cuando se requiere de un estudio exploratorio y no estructurado de la investigación. Esta metodología se considera una aproximación dentro de la investigación de tipo cualitativa que se utiliza para 
el estudio de un sujeto o de un conjunto de ellos, con la finalidad de recopilar información significativa y personal de los participantes.

Valdez (2005) explica que las RSN permiten identificar la representación que se tiene sobre la información en memoria, haciendo referencia al significado que tiene una palabra. Se trata, entonces, de redes de conceptos conectadas entre sí que tratan de explicar el conocimiento. El proceso metodológico que permitió la obtención de datos a partir de la aplicación de las RSN integró diferentes etapas en el diseño, aplicación, sistematización y análisis de la información.

\subsection{Etapa de diseño}

El primer paso para el desarrollo de la investigación fue seleccionar los términos inductores que se abordarían en el instrumento, considerando el objetivo planteado que hace referencia a la visión del alumno en el contexto de la pandemia, por lo que se seleccionaron tres, a saber: pandemia, libertad y futuro.

En un segundo momento se identificó a la población objeto del estudio la cual estuvo conformada por jóvenes alumnos y alumnas de la Universidad Nacional Autónoma de México en el nivel de pregrado y con una edad de entre 20 y 24 años. El instrumento para la recogida de la información consistió en un cuestionario con tres reactivos, uno para cada uno de los términos inductores (TI), que fue aplicado a una muestra aleatoria simple a partir de una invitación a participar con carácter voluntario. El rasgo auto determinado de la muestra no la convierte en representativa de la población universitaria; sin embargo, en estudios de corte cualitativo, esta característica no representa una limitante.

\subsection{Etapa de aplicación}

El instrumento desarrollado se dispuso para responderse en línea mediante la aplicación Google Forms y se le solicitó a los respondientes que escribieran libremente cinco palabras asociadas a cada uno de los TI. Éstas debían ser sustantivos, adjetivos o verbos. A continuación, se les pidió que jerarquizaran, de acuerdo con su criterio, cada una de las palabras en forma numérica progresiva, asignándole un valor numérico de 1 a 5 donde uno era el valor más alto y cinco el más alejado al término asociado.

\subsection{Etapa de sistematización y análisis}

Una vez que se contó con los cuestionarios respondidos, se descargaron los resultados en una hoja de cálculo donde se procedió a su sistematización, respetando la forma en la que los sujetos escribieron las palabras. Se normalizaron las palabras, a partir de la integración bajo un mismo término género y número y las derivadas de una misma raíz; igualmente, se eliminaron las no contestadas. Al integrar los términos se sumaron los valores de cada palabra definidora.

Finalmente, se procedió a sacar el valor total de la red, es decir, la cantidad de términos diferentes que resultaron de cada término inductor. Seguidamente se le otorgó el valor semántico, a partir de la multiplicación de la frecuencia de las palabras por el valor asignado por el sujeto. Para efectos de este estudio, las palabras que aparecen en primer lugar se multiplican por 10, las de segundo por 9, las de tercer lugar por 8, las de cuarto lugar por 7 y las de quinto lugar por 6.

\section{Resultados}

Esta etapa se dividió en dos fases: la primera, para obtener los indicadores propuestos por Lagunes (1993), Valores J, M, SAM, G y DSC, que se explican en la Tabla 1. 
Tabla 1

Indicadores de la red semántica

\begin{tabular}{|c|c|}
\hline Denominación & Descripción \\
\hline Valor J o tamaño de la red & Corresponde al total de palabras definidoras generadas por los sujetos. \\
\hline Valor M o peso semántico & $\begin{array}{l}\text { Es la importancia jerárquica que los sujetos dieron a las palabras y se } \\
\text { corresponde con la frecuencia con que fueron mencionadas. }\end{array}$ \\
\hline $\begin{array}{l}\text { Conjunto SAM o distancia } \\
\text { semántica }\end{array}$ & Son las 15 palabras definidoras con el mayor Valor $\mathrm{M}$. \\
\hline $\begin{array}{l}\text { Distancia conceptual o Valor } \\
\text { G }\end{array}$ & Es el grado de cercanía o dispersión entre las palabras analizadas. \\
\hline $\begin{array}{l}\text { Valor DSC o porcentaje } \\
\text { semántico }\end{array}$ & $\begin{array}{l}\text { Es el indicador de la distancia semántica que hay entre las diferentes } \\
\text { palabras definidoras que conforman el Conjunto SAM, asignando el } 100 \\
\text { por ciento a la palabra con el Valor M más alto y calculando el } \\
\text { porcentaje de los restantes a partir de éste. }\end{array}$ \\
\hline
\end{tabular}

Fuente: Elaboración propia a partir de Lagunes (2003)

En esta primera fase del análisis se tomaron los resultados de los tres términos inductores y se sistematizaron para la representación de cada una de las redes.

Una forma de representar las redes semánticas consiste en grafos con nodos que aluden a conceptos y relaciones entre éstos. Para ello, en la segunda fase, a partir de la información obtenida, se empleó el software Ucinet y Netdraw para elaborar la representación gráfica de los mapas de redes, que permitieron establecer relaciones y análisis de la información.

Figura 1

Representación Gráfica de las redes de pandemia, libertad y futuro

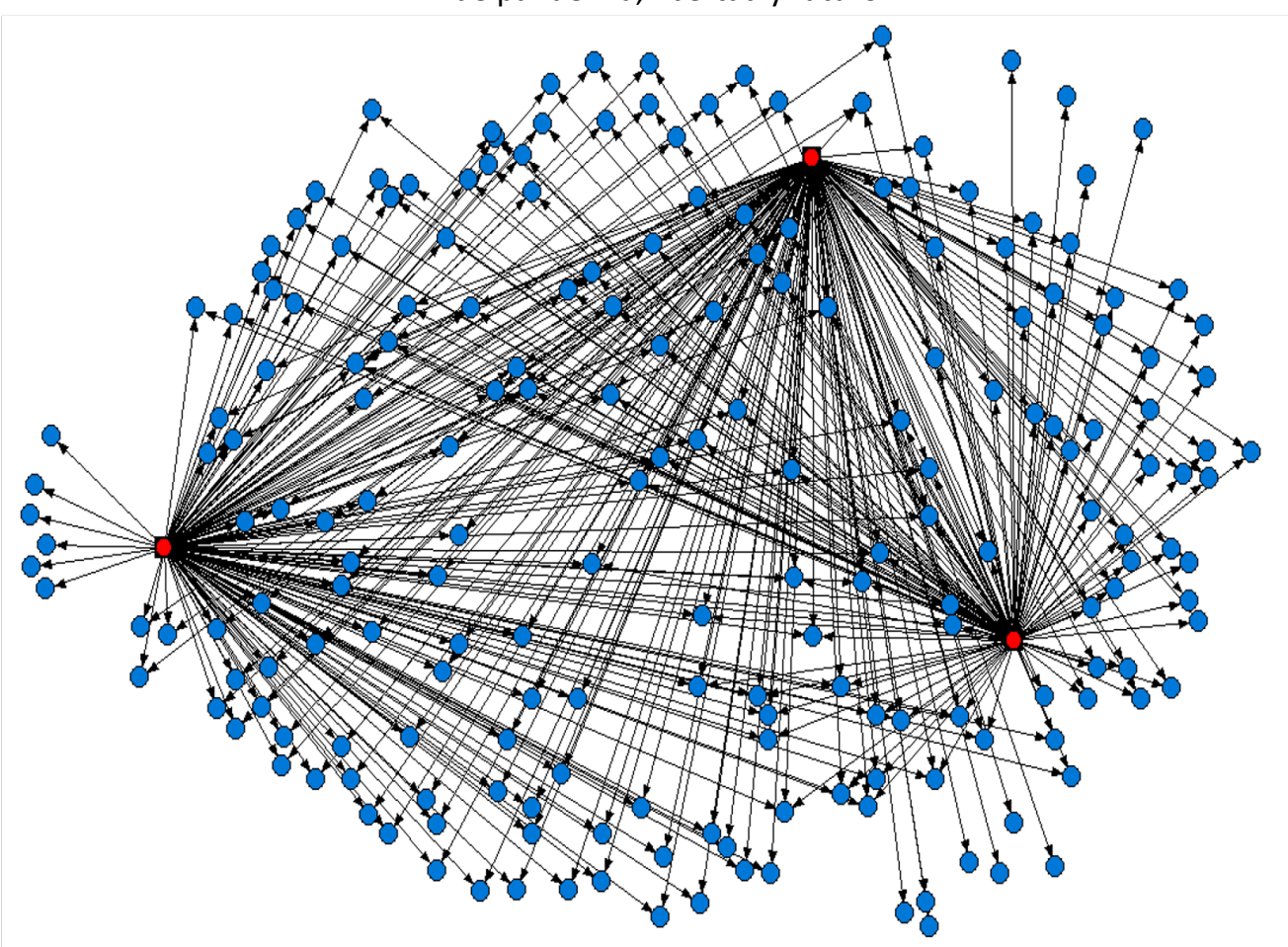

Fuente: Elaboración propia a partir de los resultados obtenidos, Netdraw, 2020. 
Esta red representa los resultados obtenidos en términos de las palabras referidas por la muestra. En la figura solamente se referencian las palabras que aparecen en el núcleo de cada una de las redes, así como las que tienen coincidencia en cada una de las redes y las que tienen coincidencia en al menos dos de los términos inductores. Se aprecia la riqueza de la red: 48 términos referidos aparecen en los tres inductores; mientras que 150 se asociaron a dos de los términos inductores. El término que más interactuó fue futuro. Adicionalmente, en la figura se muestra el Conjunto SAM o núcleos de las redes para cada uno de los $\mathrm{TI}$.

\subsection{Pandemia}

El contexto es un elemento fundamental en este estudio. Por un lado, es común a toda la población y por ende a la muestra y, por otro, el término inductor hace referencia directa a sí mismo, por lo que no se pueden desvincular en este análisis.

La pandemia en esta investigación es tanto una categoría de análisis como un eje transversal que permite una aproximación para conocer qué piensa el alumnado de la UNAM de la libertad y del futuro, pero también permite analizar cómo asocian el término pandemia. En este sentido, los resultados de los otros dos términos inductores están también condicionados por ella.

En este escenario se encuentra la universidad, es por ello por lo que cobra sentido y pertinencia este estudio. Antes de iniciar el análisis generado a partir del término, es importante mencionar que después de normalizar los resultados, el total de la red, conocido como Valor J, fue de 384. Como se verá más adelante, esta red resultó la más pequeña en comparación con las de libertad y futuro, debido a que la palabra con mayor peso, enfermedad, fue el concepto más asociado y la principal razón por la que aparecen menos palabras en esta red. EI Conjunto SAM está compuesto por las siguientes palabras: enfermedad, muerte, virus, salud, cuarentena, miedo, mundial, contagios, crisis, coronavirus, encierro, aislamiento, cuidados, confinamiento y peligro. En la Tabla 2 se aprecia la conformación del Conjunto SAM de esta red.

Tabla 2

Conjunto SAM, Valor M

y Valor DSC de pandemia

\begin{tabular}{lll}
\hline Conjunto SAM & Valor M & DSC \\
\hline Enfermedad & 2,078 & 100 \\
Muerte & 874 & 42 \\
Virus & 590 & 28.39 \\
Salud & 560 & 26.94 \\
Cuarentena & 441 & 21.22 \\
Miedo & 351 & 16.89 \\
Mundial & 338 & 16.26 \\
Contagios & 326 & 15.68 \\
Crisis & 282 & 13.57 \\
Coronavirus & 275 & 13.23 \\
Encierro & 267 & 12.84 \\
Aislamiento & 262 & 16.6 \\
Cuidados & 242 & 11.64 \\
Confinamiento & 194 & 9.33 \\
Peligro & 169 & 8.13 \\
Fuente: Elaboración propia a partir de los resultados obtenidos, 2020
\end{tabular}

En la Figura 2 se ilustra el núcleo de la red representado por las palabras con los pesos semánticos más altos. Las palabras que el alumnado universitario asocia con la pandemia y que poseen un peso semántico alto son, en su mayoría, negativas, exceptuando salud y cuidados que fueron clasificadas como positivas y la palabra mundial 
con carácter neutro, por lo que se puede identificar claramente que el TI es asociado de forma negativa en la población de alumnos universitarios.

Figura 2

Representación gráfica del núcleo

de la red pandemia (Conjunto SAM)

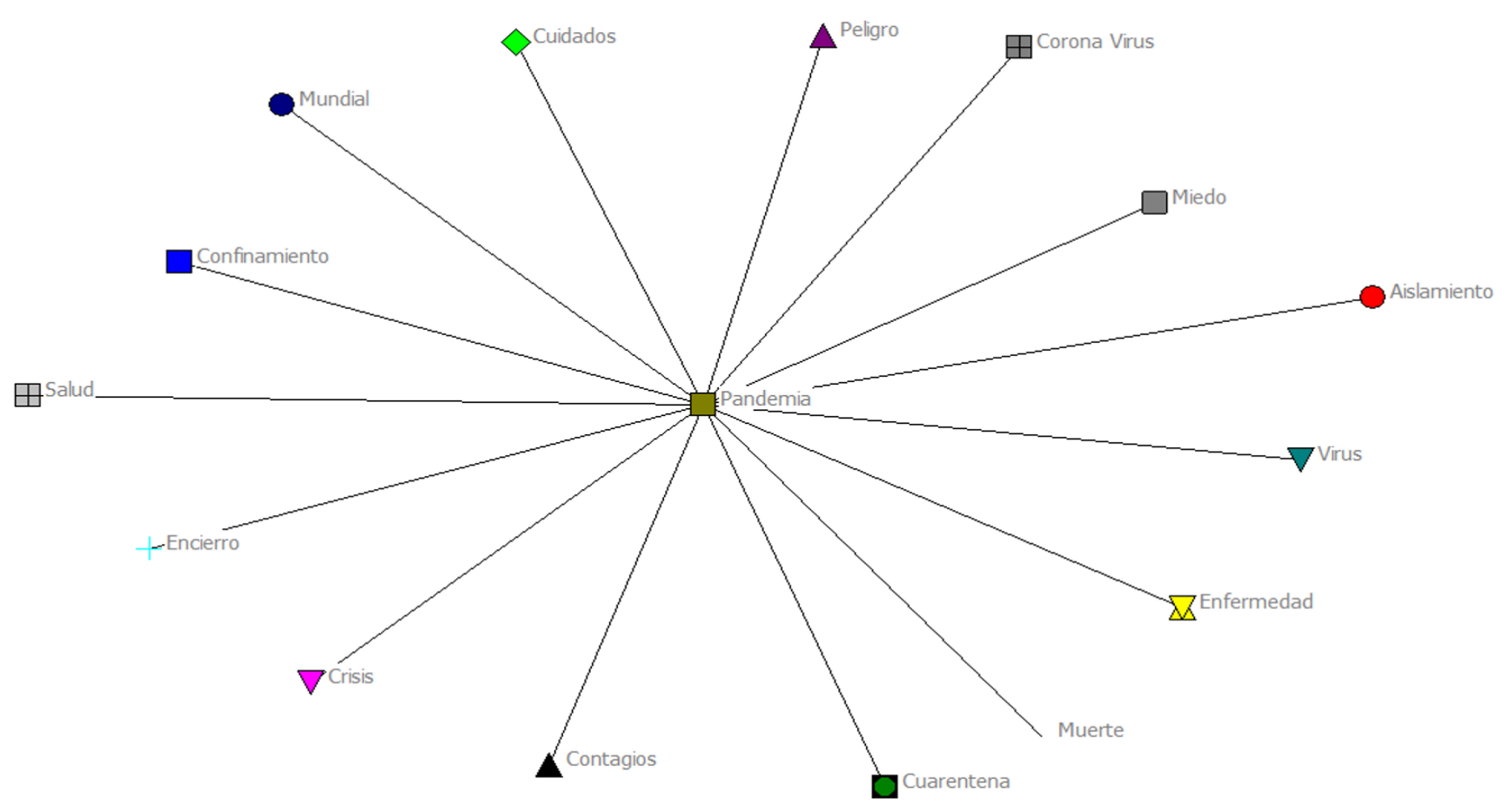

Fuente: Elaboración propia a partir de los resultados obtenidos, Netdraw, 2020

De acuerdo con los resultados, dos conceptos que fácilmente se asocian con pandemia y que forman parte del estudio son cuarentena que representa un $21.2 \%$ del núcleo de la red y aislamiento con un $16.6 \%$; finalmente, otra palabra que no forma parte del núcleo de la red, pero sí del Valor J es distanciamiento.

\subsection{Libertad}

Al igual que el resto de la población, los jóvenes encuestados vieron reducida su libertad a partir de marzo de 2020, obligados no sólo a estudiar a distancia, mediados por las tecnologías, sino a permanecer en sus casas reduciendo las posibilidades de socialización, de ocio y de movilidad en general. Es posible aventurar que esta situación genera incertidumbre, ansiedad y descontrol respecto a la interiorización del concepto de libertad adquirido hasta ese momento, por lo que cabría esperar significados de frustración respecto a lo que se asuma como libertad. Contrariamente a lo esperado, los resultados parecen alentadores.

A partir del término inductor de libertad, la red de palabras recogida por quienes respondieron la encuesta arrojó un total de 452 términos asociados, cada uno de ellos con diferentes frecuencias, que sugieren una gran variedad de concepciones en torno a la libertad. Este universo de palabras se clasificó en tres niveles: positivos, negativos y neutros. Los criterios para este atributo fueron determinados en función del contexto en el que viven estos jóvenes actualmente, aunque se reconoce que no tienen un significado unívoco.

Las frecuencias obtenidas sugieren que los jóvenes encuestados atribuyen a la libertad significados predominantemente positivos, alcanzando un $90.2 \%$, mientras que los términos negativos y neutros alcanzaron un 5 y un $4.8 \%$ respectivamente. 
Tabla 3

Frecuencia de términos positivos, negativos

y neutros en la red de libertad

\begin{tabular}{lccc}
\hline & Frecuencia & Porcentaje & Ejemplos \\
\hline Positivos & 15,191 & 90.2 & felicidad, derecho, bienestar, esperanza \\
Negativos & 845 & 5.0 & difícil, prisión, efímera, cárcel, encierro, injusticia \\
Neutros & 813 & 4.8 & mentalidad, nación, calles, bandera, afuera \\
Total & 16,849 & 100 & \\
\hline
\end{tabular}

Se identificaron como núcleo de la red (Conjunto SAM) los 15 términos con más menciones, es decir, con mayor peso semántico y se encontraron los siguientes resultados:

Tabla 4

Conjunto SAM, Valor M y

Distancia de la red de libertad

\begin{tabular}{lcc}
\hline \multicolumn{1}{c}{ Conjunto SAM } & Valor M & DSC \\
\hline Felicidad & 1,058 & 100 \\
Derecho & 976 & 92.24 \\
Expresar & 765 & 72.3 \\
Responsabilidad & 590 & 55.76 \\
Autonomía & 571 & 53.96 \\
Independencia & 559 & 52.83 \\
Salir & 517 & 48.86 \\
Decisión & 495 & 46.79 \\
Paz & 359 & 33.93 \\
Liberación & 308 & 29.11 \\
Tranquilidad & 293 & 27.69 \\
Elección & 254 & 24 \\
Voluntad & 242 & 22.87 \\
Respeto & 187 & 17.67 \\
Pensamiento & 183 & 17.29 \\
\hline Fente: Elaboracionn & 105 r & \\
\hline
\end{tabular}

Fuente: Elaboración propia a partir de los resultados obtenidos, 2020.

En la Figura 3 se aprecia el núcleo de la red. 
Figura 3

Representación gráfica del núcleo de

la red libertad (Conjunto SAM)

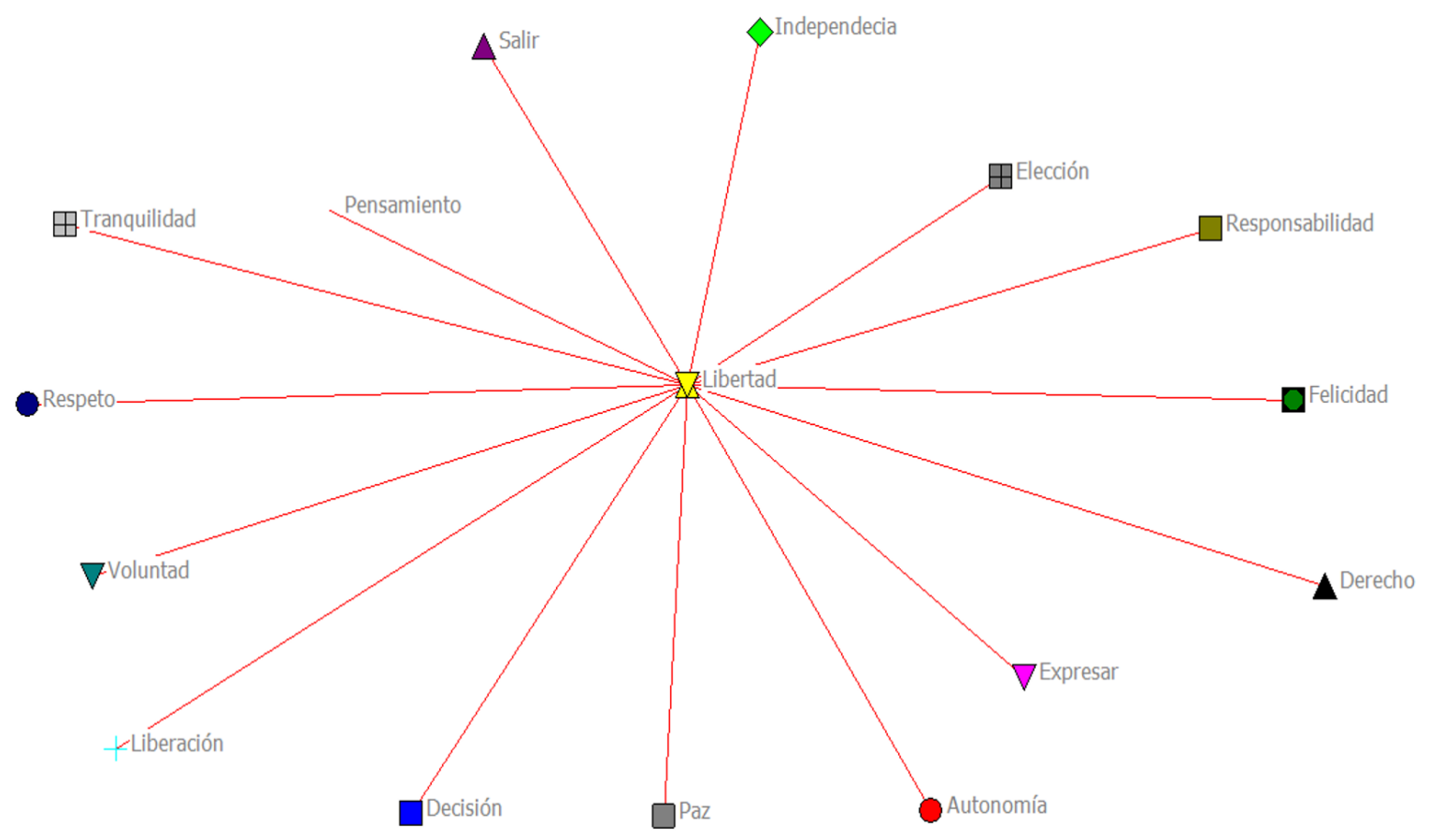

Fuente: Elaboración propia a partir de los resultados, Netdraw, 2020

La totalidad de los términos del Conjunto SAM expresan ideas positivas, siendo la de felicidad la que alcanzó la mayor frecuencia. Es de destacar que los términos encontrados como núcleo de la red sugieren que los jóvenes dan a la libertad un significado aspiracional, asociado a conceptos que identifican como positivos en su vida.

Los términos de responsabilidad, respeto y autonomía sugieren que para los jóvenes la libertad es un concepto que requiere de su participación activa. Los términos autonomía, decisión, independencia, elección y voluntad, por su parte, sugieren que los jóvenes la consideran como la posibilidad de elección independiente y autónoma.

Así, la libertad se concibe entre estos y estas jóvenes estudiantes de educación superior como un bien al que aspiran, pero también del que disfrutan, desde su libertad subjetiva que no se ha alterado sustancialmente con las restricciones de movilidad en los tiempos que corren.

\subsection{Futuro}

Ante el panorama explorado, vale la pena analizar e interpretar la percepción que los alumnos tienen del futuro, un término inductor cuyo Valor J fue de 443 palabras. Esto no sólo indica una variedad semántica considerable, sino la amplitud de una palabra que más allá de tener un carácter neutro, es compleja, dado que, al cuestionarnos sobre el futuro, inevitablemente se toma como punto de partida un presente que se ha visto influido por un pasado. Se alude a la concepción del tiempo y, por lo tanto, al sentido de temporalización individual, la concepción interna que cada persona le da al paso del tiempo. La temporalidad es relevante pues, como indica Currie $(2010,51)$, "es un modo de ser del cual se deriva la concepción del tiempo. En otras palabras, el tiempo no es algo que exista en el mundo, sino algo que se desprende del ser humano y que luego se proyecta en el mundo". De esta forma, conocer las asociaciones en un plano semántico a partir del futuro como término 
inductor nos permite entrever la proyección temporal de los alumnos en el momento histórico específico en el que la pandemia ha creado una nueva normalidad.

Tabla 5

Conjunto SAM, Valor M y

Distancia de la red de futuro

\begin{tabular}{lcc}
\hline Conjunto SAM & Valor M & DSC \\
\hline Incierto & 1,527 & 100 \\
Tiempo & 1,373 & 89.91 \\
Mañana & 527 & 34.51 \\
Lejano & 526 & 34.44 \\
Metas & 485 & 31.76 \\
Posterior & 335 & 21.93 \\
Impredecible & 304 & 19.90 \\
Trabajo & 267 & 17.48 \\
Éxito & 259 & 16.96 \\
Esperanza & 257 & 16.83 \\
Planes & 254 & 16.63 \\
Cambio & 251 & 16.43 \\
Porvenir & 239 & 15.65 \\
Próximo & 238 & 15.58 \\
Destino & 227 & 14.86 \\
\hline
\end{tabular}

Fuente: Elaboración propia a partir de los resultados

obtenidos en la aplicación de la asociación de palabras, 2020.

Dicha complejidad, inherente al hablar de temporalidad, queda evidenciada en el núcleo de la red, como se puede observar en la Tabla 5. Las tres palabras con mayor peso semántico demuestran la complejidad lingüística y ontológica del término futuro, el cual tiene un valor neutro. Si enmarcamos dichas palabras en el contexto de la pandemia, no sorprende que aquella con mayor peso semántico sea incierto. Si algo ha provocado el distanciamiento social es que la percepción del futuro no sea la misma que antes. Sin una fecha exacta para poner fin al confinamiento, el porvenir del mundo es aún más incierto de lo que ya era.

El regreso a actividades culturales masivas y actividades presenciales con compañeros y profesores, por mencionar sólo dos ejemplos, no tiene una fecha concreta y parece que el presente es un bucle que se repite al no haber un panorama claro respecto al fin de esta nueva normalidad. Así, "resulta difícil imaginar un futuro distinto del presente" (Ringel, 2020, s/p) y parecemos vivir bajo el yugo de lo que la antropóloga Jane Guyer (2017) denomina "presentismo forzado": "el sentimiento de estar atrapado en el presente" (En Ringel, 2020). Esto se hace más evidente si observamos que la cuarta palabra con mayor peso semántico es lejano, la cual no tiene una distancia semántica tan pronunciada respecto a la palabra con más peso semántico, lo que sugiere que, en efecto, este "presentismo" que repercute en la forma en la que los alumnos articulan su futuro.

La palabra impredecible, posicionada en el lugar 6 del Conjunto SAM, acentúa la noción de que la pandemia ha influido notoriamente en el sentido de temporalización de los alumnos. Otros conceptos que se pueden adherir a dicha línea de pensamiento son posterior, mañana, porvenir o destino, las cuales relegan al futuro a un plano que no es concebible de manera clara y que se queda en lo indefinido. Incluso, hubo palabras que, aunque no fueron lo suficientemente sólidas en peso semántico y no alcanzaron a entrar en el Conjunto SAM, fueron negativas y se encuentran ligadas a dicha atmósfera de nebulosidad temporal. Tal es el caso de palabras como preocupación, miedo y ansiedad, entre otras. 
Figura 4

Representación gráfica del núcleo

de la red futuro (Conjunto SAM)

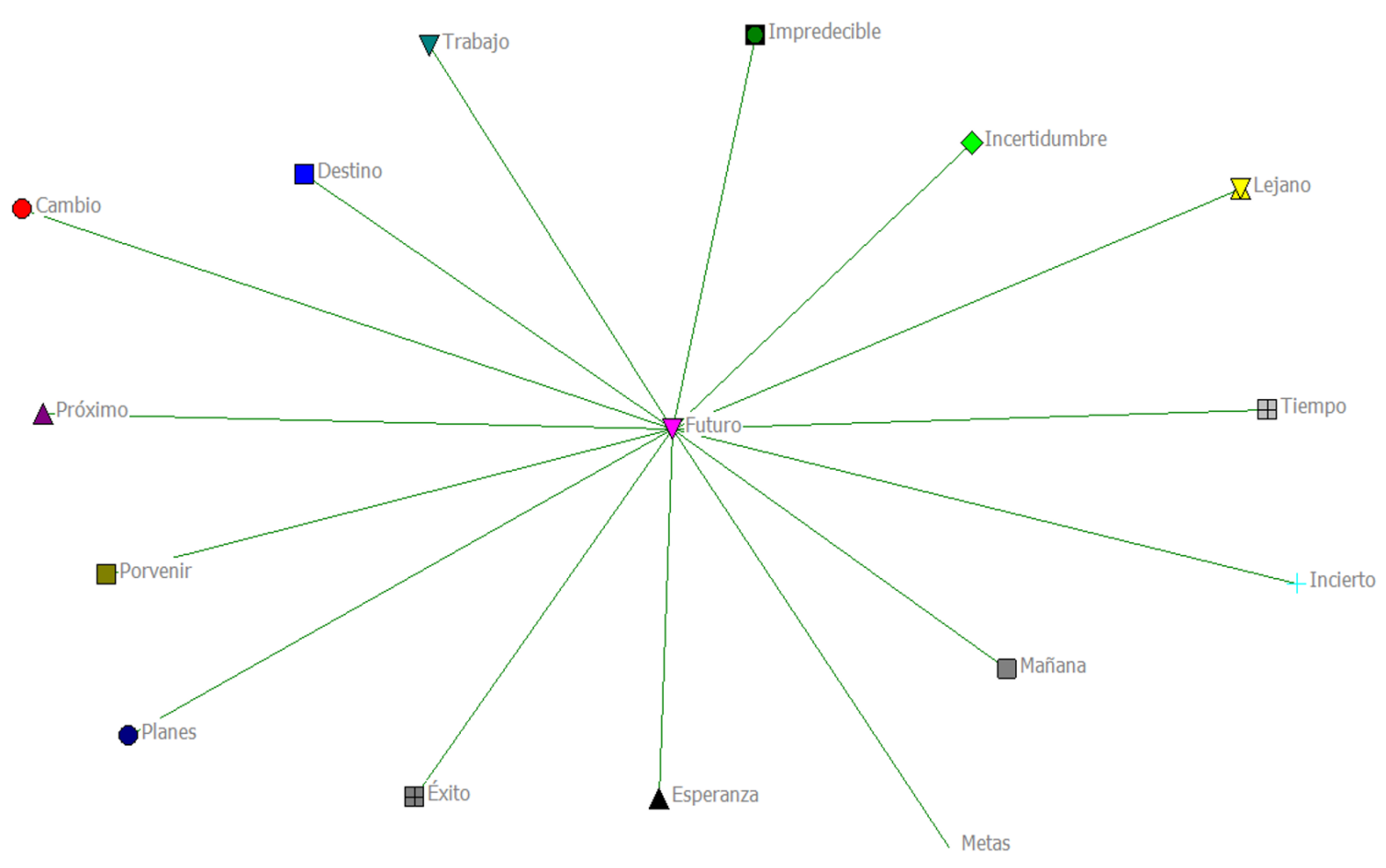

Fuente: Elaboración propia a partir de los resultados obtenidos, Netdraw, 2020

Como ya se comentó, hubo quienes asociaron el término inductor con un plano de lejanía; no obstante, también hubo quienes lo asocian como algo próximo, palabra que, aunque no tiene el mismo peso semántico que lejano, alcanzó a entrar en el Conjunto SAM. Esto refuerza la idea de que hablar del futuro apela a un sentido de temporalización subjetivo: "el tiempo del mundo, el concepto de tiempo en general es producido de manera activa por los modos de ser del humano, los cuales, subsecuentemente, temporalizan nuestro sentido del mundo externo" (Currie, 2010, 52).

No obstante, también sobresalen palabras con un aura positiva. Entre ellas, metas, trabajo, éxito, esperanza y planes indican que, más allá del contexto inmediato de incertidumbre, gran parte de los estudiantes encuestados pueden articular un futuro a partir de objetivos concretos. Bien puede inferirse que el hecho de continuar estudiando desde casa, tener que entregar tareas en fechas definidas, tomar exámenes y entablar discusiones por medio de plataformas de videollamadas, brinda un sentido de orden en medio de un caos global. En el Valor J, como se puede apreciar en la Tabla 5, se puede apreciar un conjunto de palabras que, aunque no alcanzaron un peso semántico significativo para ser parte del Conjunto SAM, sí muestran una relación estrecha con las de carácter positivo ya mencionadas. Tal es el caso de conocimiento, entusiasmo y disciplina, entre otras.

Aquí cabe resaltar que los individuos con una proyección del futuro amplia están conscientes de que su propio comportamiento juega un papel más decisivo para alcanzar una vasta gama de metas a corto y largo plazo (McInerney, 2004, 143). Esto supone que, a mayor proyección, mayor motivación y sentido de la organización. En este sentido, palabras como metas, planes o trabajo sugieren que la universidad juega un papel fundamental en la educación de ciudadanos con una proyección temporal clara en la que se puedan adaptar a tiempos de crisis en los que el futuro parece ser intangible en más de un sentido. En resumen, el término inductor futuro arrojó palabras que dan factura de una temporalización compleja que responde directamente al impasse de impredecibilidad ocasionado por la pandemia. 


\section{Discusión de resultados: Entre la enfermedad, lo incierto y la felicidad}

El coronavirus ha cambiado la forma en que se ofrece la educación y una muestra es que después de la promulgación de las regulaciones necesarias para controlar la pandemia, las escuelas y los hogares comparten en diferentes grados alrededor del mundo- el mismo espacio. Producto de esto, y de acuerdo con el informe de la UNESCO (2020), más de 861.7 millones de niños y jóvenes en 119 países se han visto afectados en todo el orbe.

Las representaciones que los jóvenes atribuyen a esta compleja situación son heterogéneos y estudios posteriores y longitudinales ayudarán a comprender el fenómeno. En esta aproximación, se han encontrado hallazgos interesantes que pueden contribuir a la búsqueda de significados; para ello, se ha realizado el análisis de cada uno de los términos inductores que integraron el estudio de manera independiente. Con objeto de ampliar el análisis y abordar conclusiones con una visión más integral, en este apartado se discuten las relaciones entre los tres términos inductores. En la Tabla 6 se aprecia el núcleo de las tres redes descritas anteriormente, dispuesta como una gran red, indicando el Valor M (peso semántico), así como el Valor DSC (distancia semántica).

Tabla 6

Núcleo de las tres redes

\begin{tabular}{lcc}
\hline Conjunto SAM & Valor M & Valor DSC \\
\hline Enfermedad & 2,078 & 100 \\
Incierto & 1,527 & 73.5 \\
Tiempo & 1,373 & 66.1 \\
Felicidad & 1,058 & 50.9 \\
Derecho & 976 & 47.0 \\
Muerte & 874 & 42.1 \\
Expresar & 765 & 36.8 \\
Virus & 590 & 28.4 \\
Responsabilidad & 590 & 28.4 \\
Autonomía & 571 & 27.5 \\
Salud & 560 & 26.9 \\
Mañana & 527 & 25.4 \\
Lejano & 526 & 25.3 \\
Metas & 485 & 23.3 \\
Cuarentena & 441 & 21.2 \\
\hline
\end{tabular}

Fuente: Elaboración propia a partir de los resultados obtenidos

Por otro lado, la Figura 5 muestra la Red Conjunto SAM de los tres términos inductores. La representación gráfica de esta red ilustra las 45 palabras que forman parte del Conjunto SAM de cada uno de los términos inductores en los que se centró el estudio presentado. Se puede ver claramente que hay palabras que coinciden con los tres términos y otras que presentan coincidencia de dos $\mathrm{TI}$, lo que significa o sugiere que los jóvenes proyectan sus planes a largo plazo en diversos sentidos, es decir, su visión subjetiva no sólo apunta a asuntos estrictamente de orden académico, sino que deja entrever palabras, tanto positivas, negativas, como neutras, que permiten 
observar la manera en la que conciben su "estar en el mundo" $y$, principalmente, la manera en la que interiorizan su propio porvenir.

Figura 5

Conjunto SAM de los tres términos inductores

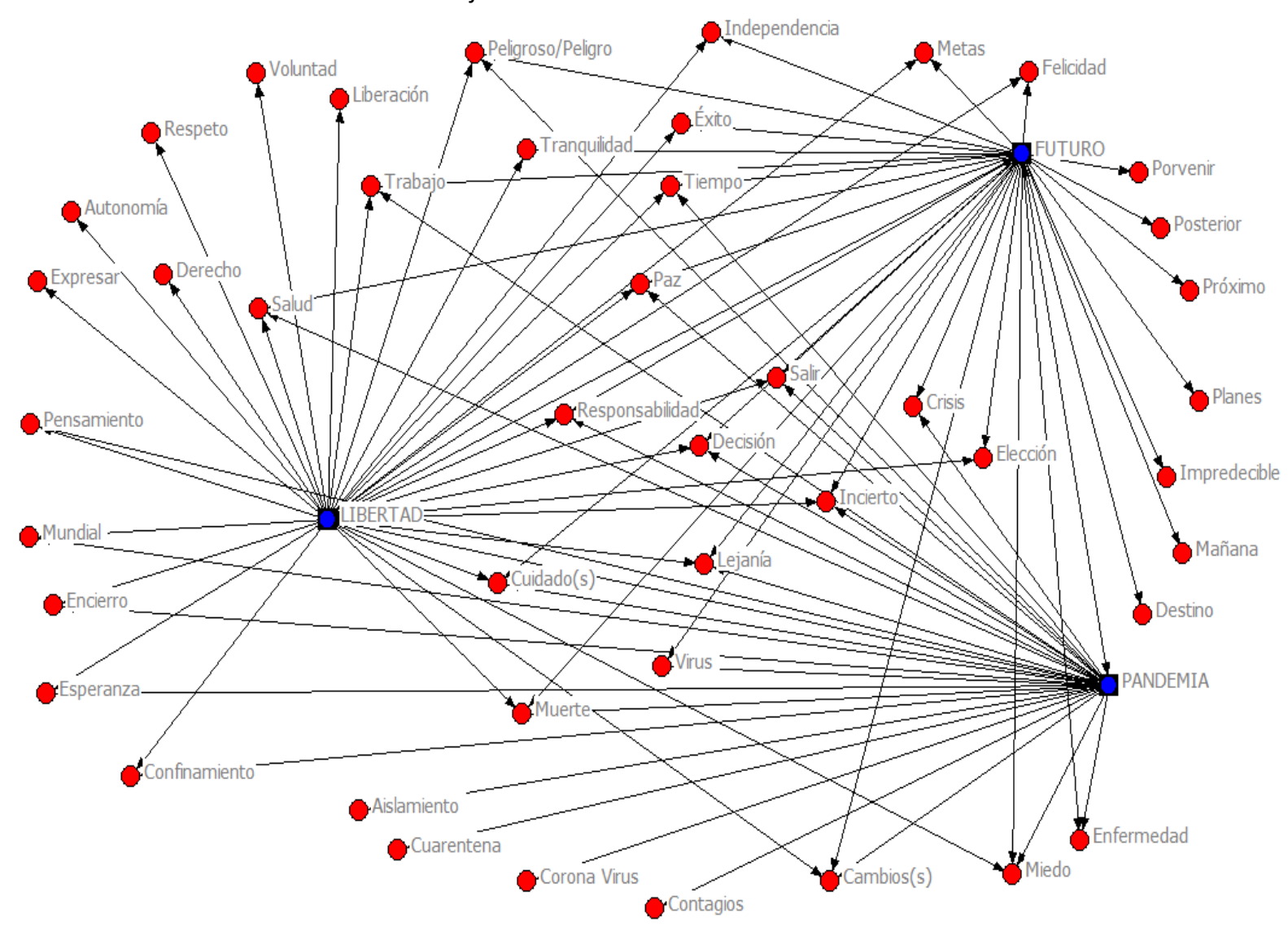

Fuente: Elaboración propia a partir de los resultados obtenidos, Netdraw 2020

Enfermedad es el concepto que aparece en primer lugar en el núcleo de la red con 2,078 menciones, además de que, como se aprecia en la Figura, proviene, tanto en el TI inductor pandemia como de futuro. Esto ocurre también con virus y con muerte. Sumando el Valor $M$ de estos tres términos, se alcanza la cifra de 3,542, que representa el $27 \%$ del total de los términos referidos. Puede suponerse, entonces, que los jóvenes tienen una clara conciencia de la situación por la que atraviesan y que no la circunscriben al ahora, sino que la visualizan en el tiempo como algo que permanecerá en sus futuros a mediano o largo plazo.

Es, justamente, el TI futuro el que tuvo más coincidencias con los otros dos, lo cual sugiere que los respondientes articulan su futuro hacia diversas dimensiones. Por un lado, su visión recayó en inquietudes vinculadas claramente con la contingencia sanitaria; esto puede observarse en palabras como las ya mencionadas, lo que sugiere que perciben sus acciones futuras como algo que se ve limitado por situaciones adversas. Sin embargo, también proyectan un futuro a partir de acciones motivadas por un sentido de libertad, lo cual puede apreciarse con palabras tales como independencia, metas o elección, las cuales tienen un carácter positivo en tanto que los alumnos se conciben a sí mismos como responsables de su destino y resaltan su responsabilidad consigo mismos para conseguir un desarrollo como ciudadanos aun en tiempos de confinamiento. Cabe destacar que, a los conceptos ya mencionados en este párrafo pueden ser añadidas palabras de carácter neutro como decisión, lugar o historia que no hacen más que reforzar la noción de imprevisibilidad que ha permeado el mundo. 
Ahora bien, al analizar qué palabras tuvieron coincidencia en los tres términos inductores, resulta aún más claro que la visión de los alumnos en este momento histórico se ve atravesada por tres planos: incertidumbre, peligro y autonomía; esto es, no se sabe qué vaya a ocurrir en un futuro inmediato debido a obstáculos y peligros propiciados por la pandemia y, sin embargo, los alumnos están conscientes de sus propios planes y las facultades con las que cuentan para llevarlos a cabo, es decir, interiorizan un sentido de independencia.

Finalmente, vale la pena la representación (en la Figura 6) de los conceptos que provienen de todo el universo y que coinciden en los tres términos inductores.

\section{Figura 6}

Red Coincidencia de conceptos en los tres términos inductores

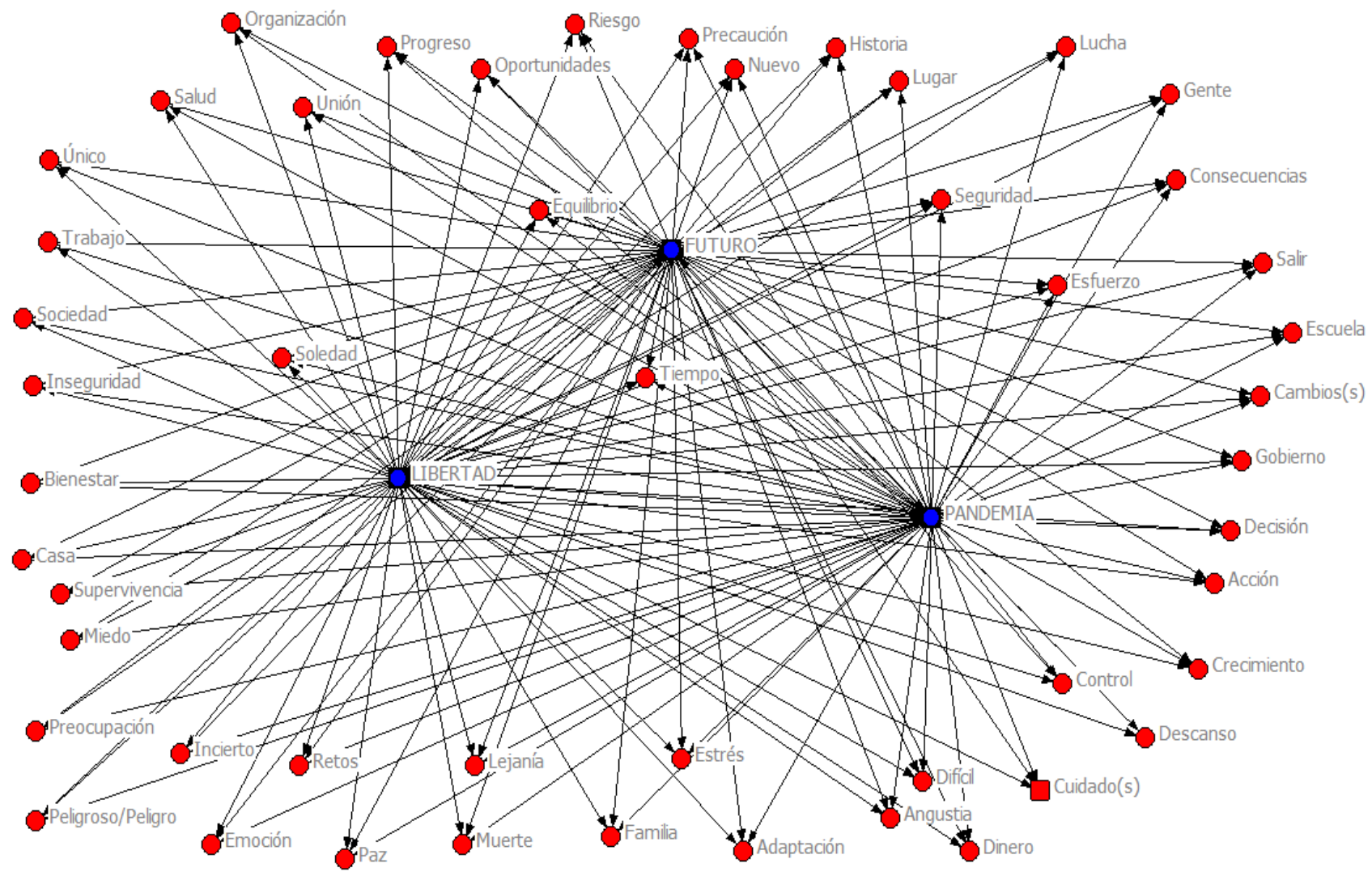

Fuente: Elaboración propia a partir de los resultados obtenidos, Netdraw 2020

Por un lado, de entre los conceptos que coinciden en los tres términos inductores hay palabras muy abstractas - como incierto, tiempo - que no hacen más que reproducir la sensación de incertidumbre producida por el efecto desconcertador que ha dejado la pandemia en prácticamente todos los contextos en los que se desenvuelve el ser humano.

Esto último va de la mano con una sensación de amenaza expresado en algunos de los conceptos que encontraron cabida en los tres términos inductores, entre los cuales figuran miedo, amenaza, muerte y enfermedad. Si bien para esta generación de estudiantes una pandemia es algo que no tiene precedentes, las palabras elegidas dan cuenta del impacto negativo que ha traído consigo la irrupción de la pandemia en el día a día de los y las estudiantes. Esto da cuenta de que están conscientes que, a pesar de que la vida continúe dentro y fuera de la universidad, se tendrán que enfrentar a obstáculos que serán un reto para su desarrollo no sólo como alumnos, sino como ciudadanos. 
Otro de los planos que quedó evidenciado en las palabras que coincidieron en los tres términos inductores fue el de la autonomía, dado que libertad arrojó conceptos que se relacionan estrechamente con una noción de autoconciencia respecto a las facultades de los estudiantes para concretar actividades a futuro. Esto puede apreciarse en palabras como retos, decisión, progreso, las cuales sugieren que, a pesar de los obstáculos y el sentimiento de impasse generados por la pandemia, los alumnos tienen una proyección futura a largo plazo que los sitúa realizando acciones de desarrollo y crecimiento personal.

El futuro representa un gran desafío para la comunidad educativa, más allá de la adaptación a las clases virtuales, implica estar dispuestos a los cambios y a vivir con incertidumbres, pero con la esperanza que la libertad impone. Como sociedad no queda más que transformarnos y guiar dicha transformación considerando los factores que conllevan al ser humano a cambios de acuerdo con su propio nivel de aprendizaje y adaptación.

\section{Referencias}

Cassell E. (2004). The Nature of suffering and the goals of medicine. Second Edition. New York: Oxford University press

Cervera R., A (s/a), Sobre el significado de las palabras en español. Diálogos de la lengua. Madrid: Universidad Complutense

Cuba, M. y Campuzano, J. (2017) Explorando la salud, la dolencia y la enfermedad. Rev Med Hered. 28, $116-121$

Currie, M. (2010). About Time: Narrative, Fiction and the Philosophy of Time. Edimburgo: Edinburgh University Press

Gaceta Médica (2020). Concepto de enfermedad. https://gacetamedica.com/?s=enfermedad

García-Cabrero B. (2020). Covid-19: impacto, desafíos y oportunidades para la Educación. Programa de Estudios sobre la Ciudad, UNAM. [Video]. Recuperado de: https://www.youtube.com/watch?v=qtlaCD_-8gM

Kroenke K. (2014) Practical and Evidence-Based Approach to Common Symptoms: A Narrative Review. Ann Intern Med 161, 579-586. DOI: https://10.7326/M14-0461

Lagunes, I. (1993). Las redes semánticas naturales, su conceptualización y su utilización en la construcción de instrumentos. Revista de Psicología Social y Personalidad 11, 81-97

Lloyd, M. (2020). Desigualdades educativas y la brecha digital en tiempos de COVID-19. En H. Casanova. H. (Coord.), Educación y pandemia: una visión académica (115-121). Ciudad de México: Universidad Nacional Autónoma de México, Instituto de Investigaciones sobre la Universidad y la Educación

McInerney, D. M. (2004). A Discussion of Future Time Perspective. Educational Psychological Review. 16(2), 141-151

Morin, E. (2000) Antropología de la libertad. Gazeta de Antropología, 16(01). Recuperado de: http://hdl.handle.net/10481/7495

Ringel, F. (2020). Coronavirus: how the pandemic has changed our perception of time. Durham University. Recuperado de https://www.dur.ac.uk/research/news/item/?itemno=41829

Rodríguez, G., Gil, J. y García, E. (2001). Metodología de la investigación cualitativa. Málaga: Ediciones Aljibe Saussure, F.(1945). Curso de lingüística general. Buenos Aires: Losada 
Save Our Future (2020). Averting an Education Catastrophe for the World's Children. Recuperado de: https://saveourfuture.world/wp-content/uploads/2020/10/Averting-an-Education-Catastrophe-for-theWorlds-Children_SOF_White-Paper.pdf

UNESCO (2020). Diálogo sobre el impacto de la crisis del coronavirus COVID-19 en las IES. Respuestas a la emergencia y transformación digital de las universidades en Iberoamérica. Recuperado de: https://www.iesalc.unesco.org/2020/07/17/dialogo-sobre-el-impacto-de-la-crisis-del-coronavirus-covid19-en-las-instituciones-de-educacion-superior-respuestas-a-la-emergencia-y-transformacion-digital-de-laeducacion-superior/

Valdez, J. (2005). Las redes semánticas naturales, usos y aplicaciones en psicología social. México: UAEM

Wittgenstein, L. (1988). Investigaciones filosóficas. Barcelona: UNAM-Crítica

World Health Organization (2006). Constitution of the World Health Organization

Esta obra está bajo una Licencia Creative Commons

Attribución-NoCommercial 4.0 International

\section{(cc) EY-NC}

